\title{
Apoptosis induction in renal cell carcinoma by TRAIL and $\gamma$-radiation is impaired by deficient caspase- 9 cleavage
}

\author{
U Ramp', E Caliskan', C Mahotka', A Krieg', S Heikaus', HE Gabbert' and CD Gerharz*,I \\ 'Institute of Pathology, Heinrich Heine University, Moorenstr. 5, D-40225 Duesseldorf, Germany
}

TNF-related apoptosis-inducing ligand (TRAIL APO-2L) is a member of the TNF family and induces apoptosis in cancer cells without affecting most non-neoplastic cells. The present investigation is focused on apoptosis induction by combined exposure to TRAlL and ionising radiation (IR) in human renal cell carcinoma (RCC) cell lines. Here, we demonstrate that all RCC cell lines coexpress TRAIL and the death-inducing receptors, TRAIL-RI and TRAIL-R2. Exposure to TRAIL alone induced marked apoptosis in three out of eight RCC cell lines. Combined exposure to TRAIL and IR resulted in a sensitisation to TRAIL-induced apoptosis in one RCC cell line only. Enhanced apoptosis induction by TRAIL in combination with IR was paralleled by an increase in PARP cleavage and activation of executioner caspase-3, whereas caspases-6 and -7 were not involved. Moreover, exposure to TRAIL and/or IR resulted in a marked activation of initiator caspase-8, possibly augmented by the observed reduction of inhibitory c-FLIP expression. In contrast to other tumour types, activation of initiator caspase-9 was not detectable in our RCC model system after exposure to TRAIL and/or IR. This lack of caspase- 9 activation might be related to an impaired 'crosstalk' with the caspase- 8 pathway as suggested by the missing Bid cleavage and to the appearance of an XIAP cleavage product known to inhibit caspase-9 activation. Deficient activation of caspase-9, therefore, might contribute to the clinically known resistance of human RCC against IR and also argues against an effective combination therapy with TRAIL and IR in this tumour type.

British Journal of Cancer (2003) 88, I800- |807. doi:I0.1038/sj.bjc.6600984 www.bjcancer.com

(c) 2003 Cancer Research UK

Keywords: renal cell carcinoma; apoptosis induction; TRAIL; ionising radiation; signal transduction pathways; caspases

Resistance of malignant tumours including human renal cell carcinoma (RCC) to chemotherapy and ionising radiation (IR) remains a major problem in oncology and is, at least in part, explained by defects in apoptotic pathways (Lowe et al, 1993; Mulders et al, 1997; Müller et al, 1998; Zhivotovsky et al, 1999; Verheij and Bartelink, 2000; Igney and Krammer, 2002). Especially the pathways of IR-induced apoptosis are not well understood so far. It is thought, however, that IR-induced apoptosis is primarily executed via release of cytochrome $c$ from mitochondria and subsequent activation of the caspase-9 pathway (Zhivotovsky et al, 1999; Belka et al, 2000, 2001; Newton and Strasser, 2000; Joseph et al, 2001; Rudner et al, 2001). In addition, activation of caspase-8 has been observed during IR-induced apoptosis, which could be related to the activation of TRAIL-R2 death receptors (Belka et al, 2000). The corresponding TRAIL ligand (APO-2L) is a type II transmembrane protein, which induces apoptosis through the specific interaction with the two death receptors TRAIL-R1 (DR4) and -R2 (DR5), both exhibiting a death domain in their cytoplasmatic regions (for a review, see Walczak and Krammer, 2000). In addition, TRAIL also binds to the decoy receptors TRAIL-R3 (DcR1) and -R4 (DcR2), which lack a functional cytoplasmatic death domain and therefore cannot induce apoptosis. TRAIL-induced apoptosis was reported to be primarily mediated via activation of caspase-8 (Gong and Almasan, 2000;

*Correspondence: Dr CD Gerharz

E-mail: gerharz@med.uni-duesseldorf.de

Received I 5 November 2002; revised 6 March 2003; accepted I 8 March 2003
Yamanaka et al, 2000; Belka et al, 2001; Nimmanapalli et al, 2001; Suliman et al, 2001; Sun et al, 2001) but might also result from the proteolytic activation of Bid, which mediates the release of cytochrome $c$ from mitochondria, thereby additionally activating caspase-9 (Belka et al, 2001; Eggert et al, 2001; Nimmanapalli et al, 2001; Seol et al, 2001; Suliman et al, 2001; Sun et al, 2001). The simultaneous activation of both pathways, that is, the activation of caspase- 8 and caspase-9, is thought to result in an further amplification of the original apoptosis signal. Both pathways subsequently converge in the activation of executioner caspase- 3 , which in turn cleaves a set of cellular substrates resulting in apoptosis (Belka et al, 2000, 2001; Walczak and Krammer, 2000; Joseph et al, 2002).

TRAIL was shown to exhibit potent antitumour activity upon systemic administration in vivo without the deleterious side effects on normal tissues known from CD95-ligand (Ashkenazi et al, 1999; Walczak et al, 1999; Nagata, 2000). Our group (Dejosez et al, 2000) and others (Ashkenazi et al, 1999; Pawlowski et al, 2000; Oya et al, 2001) also observed responsiveness to TRAIL-mediated apoptosis in some RCC cell lines, raising the possibility that TRAIL, either alone or in combination with other therapeutic strategies, might become a cancer therapeutic for otherwise unresponsive RCCs. Thus, a synergistic enhancement of TRAIL-mediated apoptosis by different anticancer drugs could be demonstrated in RCC cell lines suggesting that TRAIL might overcome resistance of RCC cells against anticancer drug-induced apoptosis (Dejosez et al, 2000; Mizutani et al, 2002).

The combination of TRAIL with IR might become another therapeutic option in order to overcome apoptosis resistance of tumour cells and several reports could actually demonstrate 
an additive or synergistic effect in different tumour models (Chinnaiyan et al, 2000; Gong and Almasan, 2000; Belka et al, 2001; Di Pietro et al, 2001; Kim et al, 2001a; Ravi et al, 2001). As corresponding investigations are missing for RCCs so far, we analysed the effects of combined treatment with TRAIL and IR in well-characterised human RCC cell lines of the clear cell type (Gerharz et al, 1993, 1994).

\section{MATERIALS AND METHODS}

\section{Cells and culture}

All eight cell lines used in this study were derived from typical representatives of the clear cell (clearCa-2, -4, -6, -7, -14, -20, -22 and -23) type of RCC (Gerharz et al, 1993, 1994). The cell lines were maintained with Dulbeccos's modified Eagle's medium (DMEM, Gibco, Karlsruhe, FRG), supplemented with $10 \%$ foetal calf serum (FCS), penicillin and streptomycin (= standard growth medium) and cultivated at $37^{\circ} \mathrm{C}$ in an atmosphere with $5 \% \mathrm{CO}_{2}$.

\section{DNA extraction, polymerase chain reaction (PCR) amplification and analysis of p53 mutations}

Extraction of genomic DNA was performed using the QIAmp Tissue Kit (Qiagen, Hildeu, FRG) according to the manufacturer's protocol. For amplification of p53 exons 5-9, the following oligonucleotide primers were used:

exons 5 and 6: forward: $5^{\prime}$-TTC CTC TTC CTG CAG TAC TC- ${ }^{\prime}$ reverse: $5^{\prime}$-ATG TGC AAA CCA GAC CTC AG $-3^{\prime}$ exons 7 and 8: forward: $5^{\prime}$-GTG TTG TCT CCT AGG TTG GC-3' reverse: $5^{\prime}$-AAG TGA ATC TGA GGC ATA AC- $3^{\prime}$ exon 9: forward: $5^{\prime}$-GTT ATG CCT CAG ATT CAC TT- ${ }^{\prime}$ reverse: $5^{\prime}$-TTG AGT GTT AGA CTG GAA AC $3^{\prime}$

Each amplification reaction was carried out in a total volume of $50 \mu \mathrm{l}$ containing $200 \mathrm{ng}$ of genomic DNA, $100 \mathrm{pmol}$ of each primer, $10 \mathrm{nM}$ of each dNTP, $2 \mathrm{U}$ Taq polymerase and $1 \times$ PCR reaction buffer (Sigma, Seelze, FRG). After an initial denaturation step at $94^{\circ} \mathrm{C}$ for $2 \mathrm{~min}, 35$ cycles of denaturation at $94^{\circ} \mathrm{C}$ for $30 \mathrm{~s}$, annealing at $50^{\circ} \mathrm{C}$ for $40 \mathrm{~s}$, and extension at $72^{\circ} \mathrm{C}$ for $1 \mathrm{~min}$ as well as a last delay at $72^{\circ} \mathrm{C}$ for $10 \mathrm{~min}$ were performed on a PTC-100thermocycler (MJ-Research, USA). After amplification, $5 \mu \mathrm{l}$ of each PCR reaction was analysed by electrophoresis on a $1.5 \%$ agarose gel and visualised by ethidium-bromide staining.

The PCR products were purified from surplus oligonucleotides using Microspin S-300 columns (Pharmacia, Erlangen, FRG). The purified PCR products were prepared for automatic sequencing using the ABI-Prism BigDye Terminator Cycle Sequencing Kit (Perkin-Elmer, Rodgau, FRG) according to the manufacturer's protocol. Sequence analysis was carried out with the sense $\left(5^{\prime}\right)$ and the antisense $\left(3^{\prime}\right)$ primers using an ABI-Prism 310 sequencer (Perkin-Elmer, Rodgau, FRG). p53 mutations were verified by an independent PCR amplification of genomic DNA followed by a repeated DNA sequencing.

\section{RNA extraction and reverse transcription (RT) - PCR analysis of TRAIL and its receptors}

Total cellular RNA was isolated from RCC cell lines using the RNeasy kit (Qiagen, Hildeu, FRG). RNA concentration was measured by photometry at $260 \mathrm{~nm}$. The quality of total cellular RNA was verified by the integrity of $18 \mathrm{~S} / 28 \mathrm{~S}$ ribosomal RNA in ethidium bromide-stained agarose gels.

For monitoring expression of TRAIL and its R1-, R2-, R3- and R4-receptors, RT was performed using an RT-kit (Stratagene, La Jolla, USA), $5 \mu \mathrm{g}$ of total cellular RNA, $10 \mathrm{pmol}$ of gene-specific antisense primer (TRAIL-R3) or $100 \mathrm{pmol}$ random primer (TRAIL,
$\mathrm{R} 1, \mathrm{R} 2, \mathrm{R} 4$ and GAPDH) and $5 \mathrm{U}$ AMV reverse transcriptase (Promega, Madison, USA) with the corresponding RT buffer in a final volume of $30 \mu \mathrm{l}$. The reactions were incubated at $55^{\circ} \mathrm{C}$ for $1 \mathrm{~h}$.

The PCR mixture was composed as follows: $1.5 \mu \mathrm{l}$ of the cDNA solution as a template, $25 \mathrm{pmol}$ of each gene-specific primers, $12.5 \mathrm{nmol}$ of dNTPs (Stratagene, La Jolla, USA) and 2.5 U Taq polymerase (Sigma, Seelze, FRG) with the corresponding buffer in a final volume of $50 \mu \mathrm{l}$.

The following primer sequences were used:

TRAIL: forward: $5^{\prime}$-ACA GCA GTC AGA CTC TGA CAG GAT C-3' reverse: $5^{\prime}$-ACG GAG TTG CCA CTT GAC TTG CCA G-3'

TRAIL-R1: forward: $5^{\prime}$-CAG AAC GTC CTG GAG CCT GTA AC-3' reverse: $5^{\prime}$-ATG TCC ATT GCC TGA TTC TTT GTG-3'

TRAIL-R2: forward: $5^{\prime}$-GAT TGT ACA CCC TGG AGT GAC ATC G-3' reverse: $5^{\prime}$-CCA CAG TAA AGA CTT GCA AAC AAA CAC- $3^{\prime}$

TRAIL-R3: forward: $5^{\prime}$-CTG CCA GTC CTA GCT TAC TCT G-3' reverse: $5^{\prime}$-CTG CTA CAC TTC CGG CAC ATC T- $3^{\prime}$

TRAIL-R4: forward: $5^{\prime}$-GAC CCC AAG ATC CTT AAG TTC G- $3^{\prime}$ reverse: $5^{\prime}$-TGT TCT ACA CGT CCG GCA CAT C-3'

GAPDH: forward: $5^{\prime}$-ACG GAT TTG GTC GTA TTG GGC G-3 reverse: $5^{\prime}$-CTC CTG GAA GAT GGT GAT GG-3'

The initial denaturation step at $94^{\circ} \mathrm{C}$ for $4 \mathrm{~min}$ was followed by 35 cycles (or 27 cycles for GAPDH) of denaturation for $1 \mathrm{~min}$ (TRAIL and TRAIL-R1, -R2, -R3, -R4) or $30 \mathrm{~s}$ (GAPDH), annealing for $1 \mathrm{~min}$ at $55^{\circ} \mathrm{C}$ (TRAIL and TRAIL-R1, -R2, -R3, -R4) or $64^{\circ} \mathrm{C}$ (GAPDH), extension at $72^{\circ} \mathrm{C}$ for $1 \mathrm{~min}$, and a final extension step at $72{ }^{\circ} \mathrm{C}$ for $10 \mathrm{~min}$. The PCR products were separated on $3 \%$ agarose gels and the identity of the amplification products was confirmed by DNA sequencing (data not shown).

\section{Assessment of cell number after exposure to rhs TRAIL and/or IR}

Recombinant human soluble (rhs) TRAIL (Pepro Tech, Rocky Hill USA) was added to the cultures to yield a final concentration of 10 and $100 \mathrm{ng} \mathrm{ml}^{-1}$, respectively. In an other set of experiments, cultures were exposed to IR with doses of 1 or $5 \mathrm{~Gy}$. Four replicate 24-well plates were exposed to standard growth medium supplemented with 10 or $100 \mathrm{ng} \mathrm{ml}^{-1}$ rhs TRAIL or exposed to IR with 1 or $5 \mathrm{~Gy}$, respectively. Moreover, two replicate 24 -well plates with standard growth medium were first exposed to IR ( 1 or $5 \mathrm{~Gy})$ and afterwards exposed to standard growth medium supplemented with $10 \mathrm{ng} \mathrm{ml}^{-1}$ rhs TRAIL. $5 \times 10^{4}$ cells were seeded in each culture plate. As controls, two replicate 24 -well plates received inocula of $5 \times 10^{4}$ cells in standard growth medium. In each experiment, cells were harvested separately after $72 \mathrm{~h}$. Cells were not refed during this period. The assessment of cell number was performed in three independent experiments $(n=3)$. The number of cells harvested was counted by the trypan-blue exclusion method.

\section{Statistical analysis}

Interactions between rhs TRAIL and IR were analysed by the fractional inhibition method as follows: when expressed as the fractional inhibition cell viability, additive inhibition produced by both inhibitors $(i)$ occurs when $i_{1,2}=i_{1}+i_{2}$; synergism when $i_{1,2}>i_{1}+i_{2}$; and antagonism when $i_{1,2}<i_{1}+i_{2}$.

\section{Morphological assessment of TRAIL-induced apoptosis}

$1 \times 10^{4}$ cells were seeded in each chamber of eight-chamber slides (Nunc, Wiesbaden, FRG). After $24 \mathrm{~h}$, the cells were treated with 10 or $100 \mathrm{ng} \mathrm{ml}^{-1}$ rhs TRAIL and cultured for another $72 \mathrm{~h}$. As a control, tumour cells were exposed to standard growth medium. Apoptosis was determined by light microscopy of haematoxylin eosin (HE)-stained cells showing the typical morphological signs 
of apoptosis, that is, chromatin condensation and/or fragmentation into apoptotic bodies (Gerharz et al, 1999; Ramp et al, 2000, 2001).

\section{Western blot analysis}

Ten replicate $25 \mathrm{~cm}^{2}$ culture flasks, each containing inocula of $1 \times 10^{6}$ cells, were exposed to standard growth medium supplemented with rhs TRAIL $\left(10 \mathrm{ng} \mathrm{ml}^{-1}\right)$ or exposed to IR (1 Gy), respectively. Moreover, five replicate $25 \mathrm{~cm}^{2}$ culture flasks with standard growth medium were first exposed to IR (1 Gy) and afterwards exposed to standard growth medium supplemented with rhs TRAIL $\left(10 \mathrm{ng} \mathrm{ml}^{-1}\right)$. As controls, six replicate $25 \mathrm{~cm}^{2}$ culture flasks received inocula of $1 \times 10^{6}$ cells in standard growth medium. In each experiment, cells were harvested separately after $0.5,3,6,12$ and $24 \mathrm{~h}$ or after $12 \mathrm{~h}$ (for analysis of c-FLIP, FADD, Bid, phosphorylated Akt, XIAP and survivin). Cells were not refed during this period.

For Western blot analysis, tumour cells were lysed in a buffer containing $100 \mathrm{~mm} \mathrm{NaCl}, 10 \mathrm{~mm}$ Tris- $\mathrm{HCl}$ (pH 7.6), $1 \mathrm{~mm}$ EDTA (pH 8.0), $1 \mu \mathrm{g} \mathrm{ml}^{-1}$ aprotinin, $100 \mu \mathrm{g} \mathrm{ml}^{-1}$ phenylmethylsulphonyl fluoride and $1 \%$ NP40. Protein $(50 \mu \mathrm{g})$ was analysed by SDS - PAGE and protein expression levels were determined by immunoblotting with the following monoclonal or polyclonal antibodies: caspase- 3 (1:150, Cell Signaling Technology, Beverly, USA), caspase-6 ( $1: 1000$, Cell Signaling Technology, Beverly, USA) caspase-7 (clone B94-1; 1:1000, Pharmingen, San Diego, USA), caspase-8 (clone 1C12; 1:1000, Cell Signaling Technology, USA), caspase-9 (clone 1-2; 1:500, Oncogene, La Jolla, USA), Bid (1:500, Biosource, Camarillo, FRG), phosphorylated Akt (clone 4E2; $1: 1000$, Cell Signaling Technology, Beverly, USA), Fas-associated death domain-containing protein (FADD) (clone A66-2; 1:1000, Pharmingen, San Diego, USA), PARP (clone 4C10-5; 1:1000, Pharmingen, San Diego, USA), X-linked inhibitor of apoptosis proteins (XIAP) (clone 48; 1:250, Transduction Laboratories, Lexington, USA), Survivin (1:1000, Novus Biologicals, Littleton, USA) and c-FLICE-inhibitory protein (FLIP) (clone NF6, 1:10, gift from Professor Dr P Krammer, DKFZ, Heidelberg).

For detection, the ECL detection system (Fa. Amersham, Freiburg, FRG) was used according to the manufacturer's instructions. Equal loading of the gels was confirmed both by Commassie-blue staining of control gels and by reincubation of the filters with a monoclonal antibody for $\alpha$-tubulin (clone B-5-1-2; 1:5000, Sigma-Aldrich, Seelze, FRG).

\section{RESULTS}

\section{TRAIL-mediated apoptosis in human RCCs}

Reverse transcription-polymerase chain reaction RT - PCR analysis revealed coexpression of TRAIL ligand as well as apoptosisinducing TRAIL-R1 and -R2 in all RCC cell lines (Figure 1). Moreover, two different specific amplification products (120 and $217 \mathrm{bp}$ ) of TRAIL-R2 were detectable in all cell lines and verified as TRICK-2A and TRICK-2B by sequence analysis (data not shown). All RCCs expressed antagonistic TRAIL-R3 and -R4 with weak signals for TRAIL-R3 in the majority of cell lines (Figure 1).

To evaluate the extent of TRAIL-mediated apoptosis and the functionality of the TRAIL-signalling pathway, we used rhs TRAIL, thereby confronting our RCC cell lines with an uniform apoptotic signal. After exposure to rhs TRAIL (10 or $100 \mathrm{ng} \mathrm{m}^{-1}$ ) for $72 \mathrm{~h}$, a heterogeneous response was observed with a marked decrease of cell viability in only three out of eight RCC cell lines (clearCa-6, -14 and -23) (Figure 2). The decrease of cell viability after exposure to TRAIL was paralleled by a marked induction of apoptosis (Figure 3), as became evident from light microscopical evaluation of HE-stained cells, which had been shown to be a highly sensitive

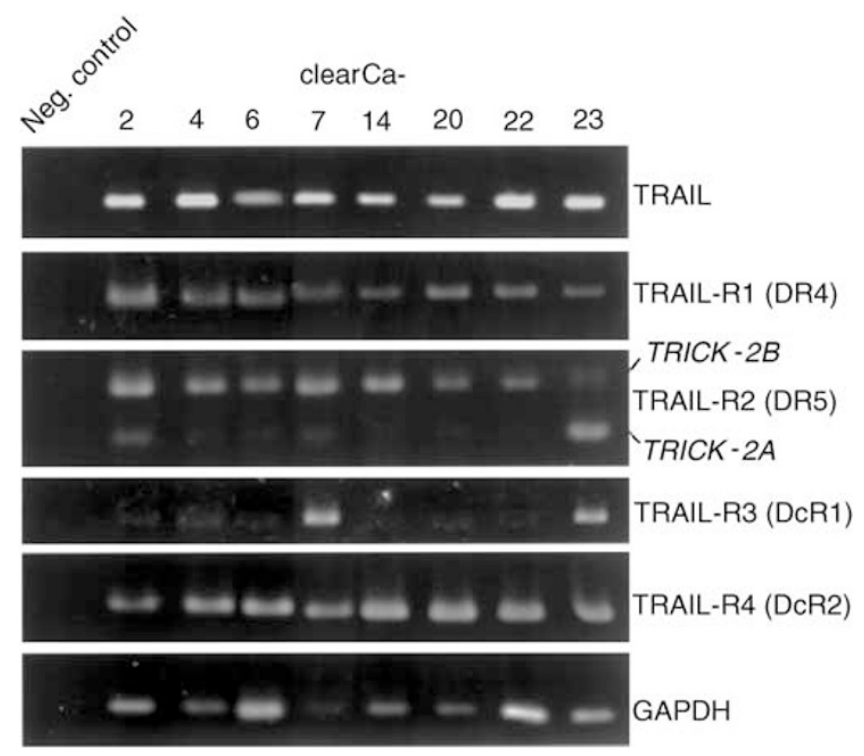

Figure I Expression of TRAIL and its receptors in eight human RCC cell lines by RT-PCR. TRICK-2A and TRICK-2B are alternative splicing variants of TRAIL-R2. GAPDH detection was used as control for integrity of RNA and $R T-P C R$ reactions.

and specific method for the assessment of apoptosis (Gerharz et al, 1999; Ramp et al, 2000, 2001).

\section{p53 status}

As wild-type p53 has been reported to be involved in apoptosis induction after exposure to TRAIL and/or IR (Lowe et al, 1993; Chinnaiyan et al, 2000), we additionally defined the mutational status of p53 in our RCC cell lines. Sequencing of p53 exons 5-9, which are the most commonly affected hot spot regions for p53 mutations in human RCC (Reiter et al, 1993), revealed p53 exon mutations in two of eight RCC cell lines only (Table 1). The p53 status, however, could not be correlated with the sensitivity to TRAIL-induced apoptosis. Thus, mutant p53 was observed in clearCa-6, which is highly TRAIL-sensitive, but also in clearCa-4, which is TRAIL-resistant.

\section{Ionising radiation sensitises to TRAIL-induced apoptosis in a minority of RCCs}

To evaluate a possible increase in sensitivity against TRAILinduced apoptosis by IR, we selected TRAIL-resistant RCC cell lines (clearCa-2, $-4,-7,-20$ and -22) and the most TRAIL-sensitive cell line (clearCa-6) for the combined exposure to TRAIL $\left(10 \mathrm{ng} \mathrm{ml}^{-1}\right)$ and clinically relevant IR doses (1 or $\left.5 \mathrm{~Gy}\right)$. In these experiments, combined exposure to TRAIL and IR resulted in a sensitisation effect with marked enhancement of apoptosis in one RCC cell line only (clearCa-22) (Figure 4). Interestingly, this cell line did not harbour a mutation in the p53 'hot spot' exons and had shown increased expression of TRAIL-R2 protein after IR by Western blot analysis (data not shown). In accordance, a strong enhancement of apoptosis induction also became evident from a marked increase in PARP cleavage after combined exposure of clearCa-22 to TRAIL and IR, whereas exposure to either TRAIL or IR alone did not result in increased levels of PARP cleavage (Figure 5A). Combined exposure of clearCa-22 to TRAIL and IR also resulted in a marked caspase- 3 activation, whereas exposure to either TRAIL or IR alone induced no (TRAIL) or a weak (IR) caspase- 3 cleavage only (Figure $5 \mathrm{~B}$ ). In contrast, activation of executioner caspase- 6 and -7 was not detectable (Figure 5C, D). 


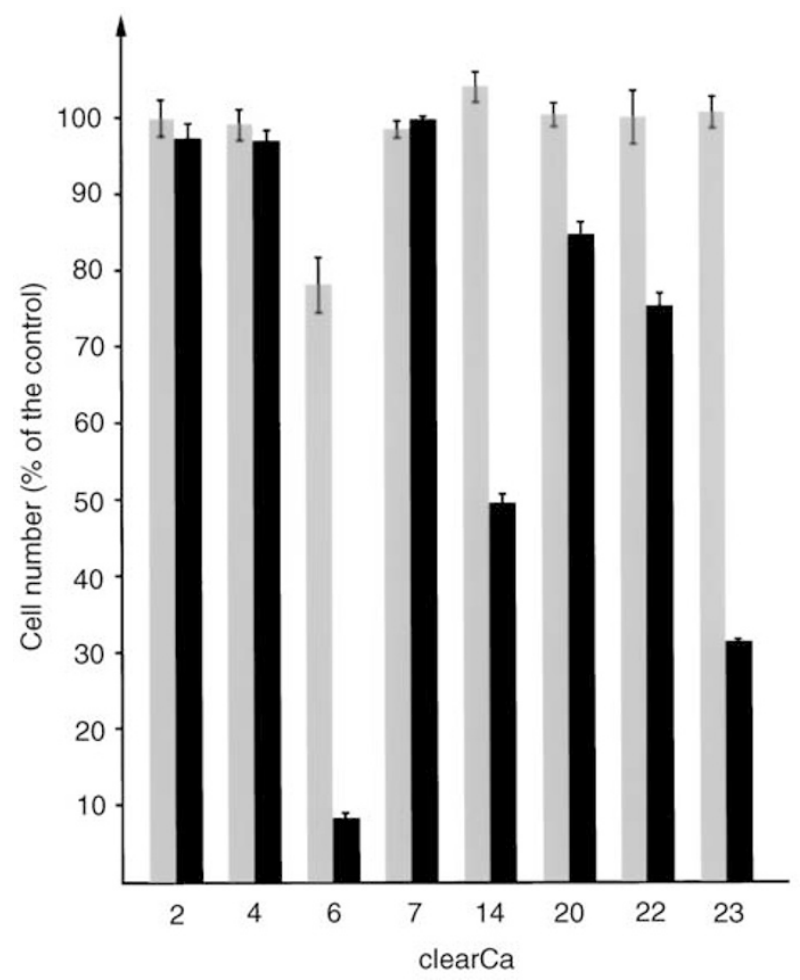

Figure 2 Response of human RCC cell lines to TRAlL-induced cell death. Cells were cultured for $72 \mathrm{~h}$ in the presence of TRAIL (grey bars: $10 \mathrm{ng} \mathrm{ml^{-1 }}$ TRAIL; black bars: $100 \mathrm{ng} \mathrm{ml}^{-1}$ TRAIL) and the number of surviving, nonapoptotic cells is demonstrated in percentage of viable cells in the control (bars represent the s.d).
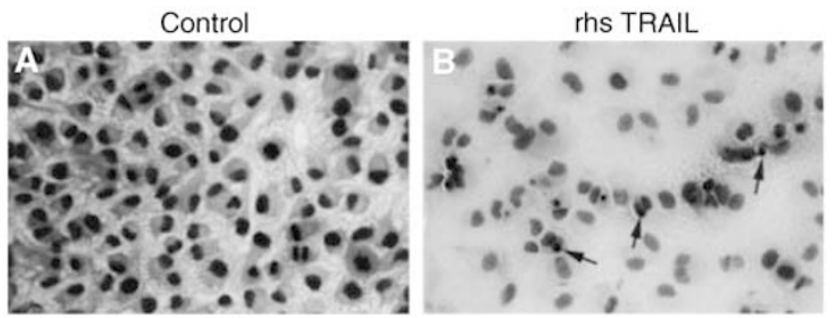

Figure 3 Marked induction of apoptosis (arrows) and marked reduction of cell density in clearCa-6 cells after exposure to TRAIL $\left(100 \mathrm{ng} \mathrm{ml}^{-1}\right)$ (B) when compared to the control $(\mathbf{A})$. (Before TRAll treatment, about $2 \%$ of the cells exhibited morphological features of apoptosis. The proportion of apoptotic cells after TRAIL treatment, however, cannot exactly be determined, because most apoptotic cells detached from the bottom of the culture flask and formed a not exactly quantifiable mass of cell detritus in the supernatant)

Table I p53 mutation status

\begin{tabular}{ll}
\hline Cell line & p53 (wild-type $(\mathbf{w t})$ or mutation $(\mathbf{m t})$ ) \\
\hline 2 & mt in noncoding region: codon 306: CGA $\rightarrow$ CAA \\
4 & mt: exon 8, codon 273: CGA $\rightarrow$ CAT \\
6 & mt: exon 8, codon 290: CGC $\rightarrow$ CAC \\
7 & wt \\
14 & wt \\
20 & wt \\
22 & mt in noncoding region: codon 331: CTT $\rightarrow$ CTC \\
23 & wt \\
\hline
\end{tabular}
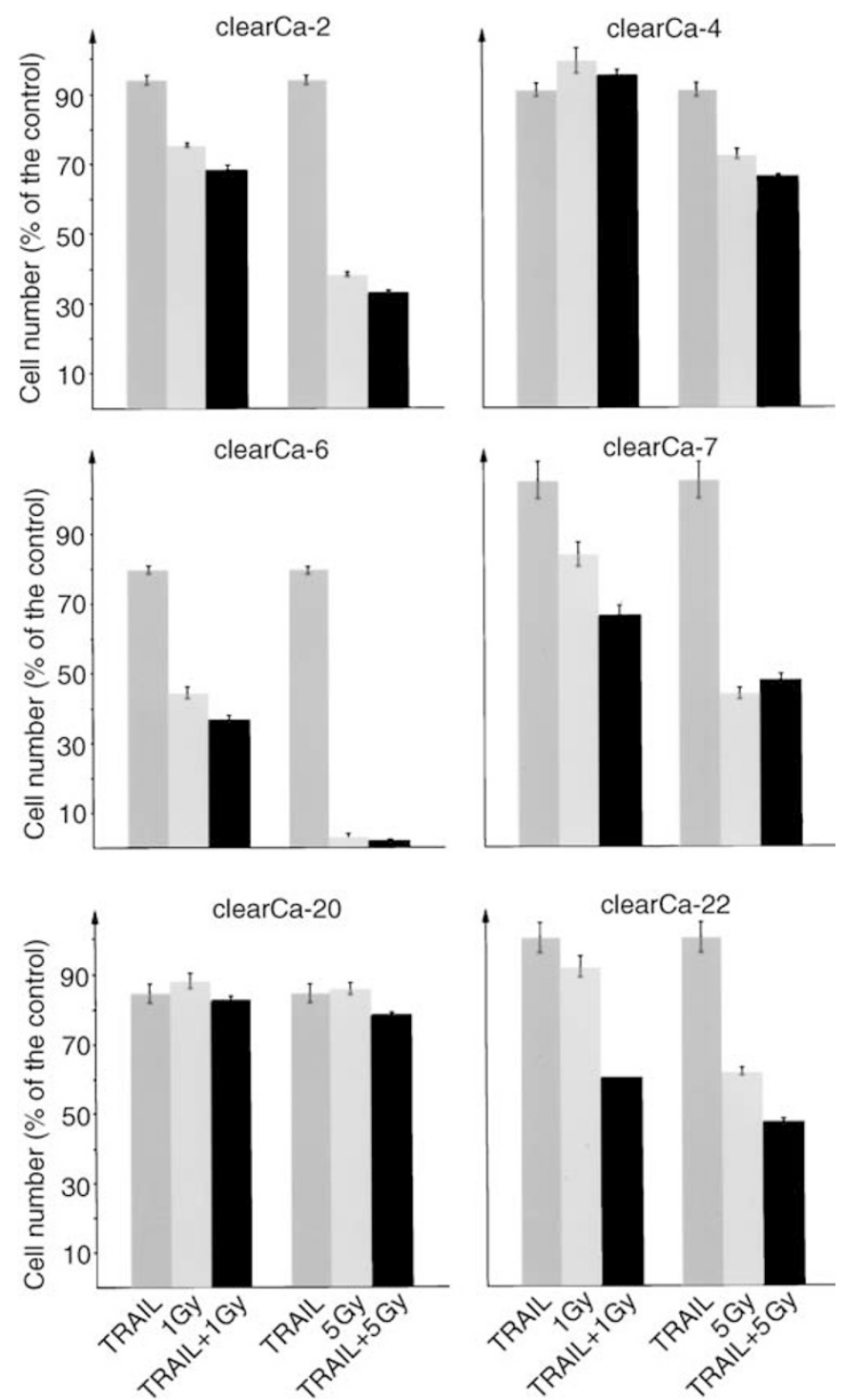

Figure 4 Sensitisation to TRAlL-induced apoptosis by IR in one (clearCa-22) out of six human RCC cell lines. RCC cell lines were cultured for $72 \mathrm{~h}$ in the presence of TRAIL $\left(10 \mathrm{ng} \mathrm{ml}^{-1}\right.$ ) or IR (I or $5 \mathrm{~Gy}$ ) alone or in combination and the number of surviving, nonapoptotic cells is demonstrated in percentage of viable cells in the control (bars represent the s.d).

\section{Cleavage of caspase-8, but not of caspase- 9 triggers TRAIL- and/or IR-mediated apoptosis in RCC}

Since the sensitisation to apoptosis induction after combined exposure to TRAIL and IR may be due to the simultaneous activation of the caspase- 8 and -9 pathways, we next analysed the activation of these distinct apoptosis pathways in clearCa-22.

As shown in Figure 6A, cleavage of initiatior caspase- 8 into its fragments ( $\mathrm{p} 43$ and $\mathrm{p} 41$ ) became evident in clearCa-22 after exposure to TRAIL and/or IR. Of note, caspase- 8 activation after combined exposure to TRAIL and IR did not exceed the effects of each treatment alone, although only combined exposure had resulted in an increased cleavage of caspase-3. Interestingly in this context, expression of caspase-8-inhibitory c-FLIP (Irmler et al, 1997; Wang et al, 2000) was markedly reduced after exposure to TRAIL or IR alone and in combination, thereby probably contributing to the activation of caspase-8 (Figure 7). In contrast, no unequivocal differences in the expression of FADD became evident after exposure to TRAIL and/or IR (Figure 7). 


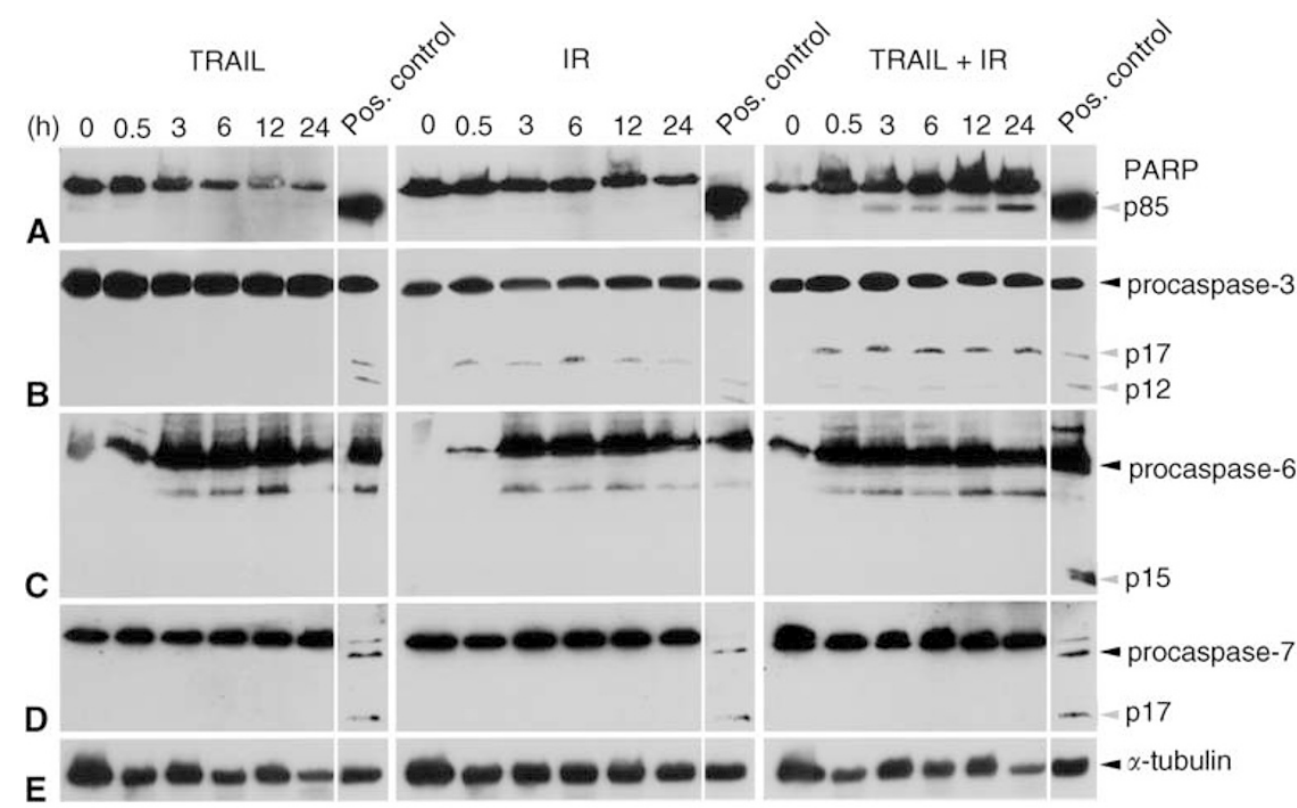

Figure 5 Western blot analysis demonstrating marked cleavage of PARP ( $885 ; \mathbf{A})$ and procaspase-3 ( $\mathrm{p} \mathrm{I7/p} \mathrm{I2;} \mathrm{B)} \mathrm{into} \mathrm{its} \mathrm{active} \mathrm{fragments} \mathrm{after} \mathrm{combined}$ exposure of clearCa-22 cells to TRAIL $\left(10 \mathrm{ng} \mathrm{m}^{-1}\right)$ and IR (I Gy). Exposure to TRAIL or IR alone did not result in increased cleavage. No cleavage products of procaspases-6 ( $/ 5 ; \mathbf{C})$ and -7 ( $/ 7$; D) in clearCa-22 cells after exposure to TRAIL or IR alone and in combination. (cleavage of PARP as well as the procaspase-3, -6, and -7 in 116 cells after exposure to $\mathrm{CHII}\left(500 \mathrm{ng} \mathrm{ml}^{-1}\right.$ ) was used as a positive control). Expression of $\alpha$-tubulin (E) shows equal amounts of protein loaded in each lane.

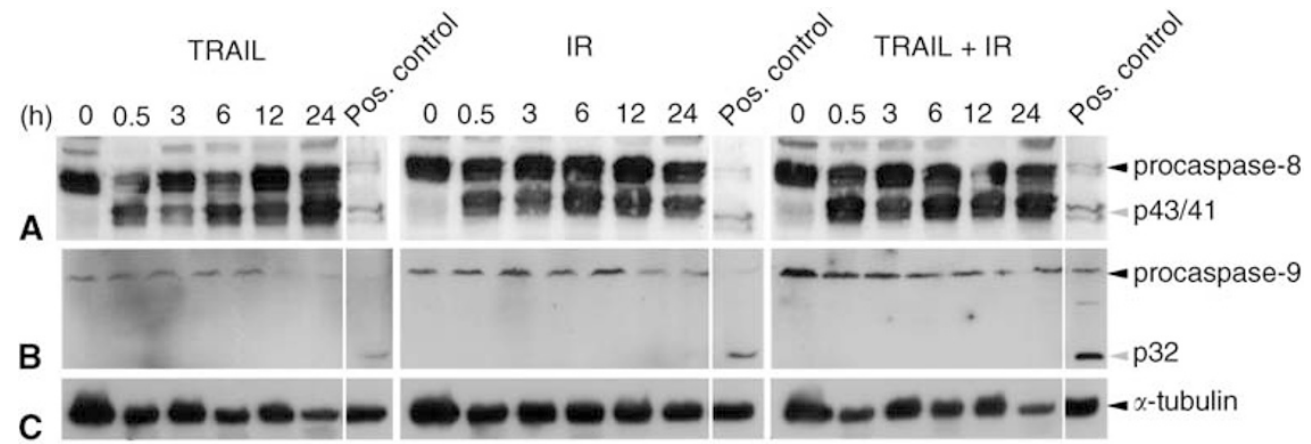

Figure 6 Western blot analysis demonstrating marked cleavage of procaspase-8 $(\mathbf{A})$ into its active $p 43$ - and p4I-fragments after exposure of clearCa-22 cells to TRAIL $\left(10 \mathrm{ng} \mathrm{ml}^{-1}\right.$ ) or IR (I Gy) alone and in combination. No cleavage of procaspase-9 (B) in clearCa-22 cells after exposure to TRAIL or IR alone and in combination. (cleavage of procaspase- 8 and -9 in $\mathrm{Jl} 6$ cells after exposure to $\mathrm{CHI} \mathrm{I}\left(500 \mathrm{ng} \mathrm{ml}^{-1}\right)$ was used as a positive control). Expression of $\alpha$ tubulin $(\mathbf{C})$ shows equal amounts of protein loaded in each lane.

In contrast to activation of the caspase-8 pathway, activation of the caspase- 9 pathway was not detectable in clearCa-22 at all (Figure 6B). Since the caspase-9 pathway was shown to be functionally involved in IR-induced apoptosis in other tumour models (Newton and Strasser, 2000; Joseph et al, 2001; Rudner et al, 2001), the impaired activation of caspase-9 might contribute to the well-known resistance of RCC to IR-induced apoptosis.

Moreover, our investigations provided first clues to the mechanisms of deficient caspase-9 activation in RCC. Thus, cleavage of Bid into tBid, which is the connecting link between the caspase- 8 and caspase- 9 pathways of apoptosis induction ( $\mathrm{Li}$ et al, 1998), could not be observed after exposure to TRAIL and/or IR (Figure 7). Failure of Bid cleavage could not be attributed to the presence of active phosphorylated Akt protein, which was not detectable at all (Figure 7). Moreover, high levels of XIAP expression were observed before and after exposure to TRAIL and/or IR (Figure 7) and, more importantly, a cleavage product of XIAP, which is known to inhibit caspase- 9 activation (Deveraux et al, 1999), appeared after exposure to TRAIL and/or IR (Figure 7).
In contrast, only low expression levels of antiapoptotic survivin, known to inhibit activation of caspase-3, -7 and -9 , were found before and after exposure to TRAIL and/or IR (Figure 7).

\section{DISCUSSION}

Ionising radiation is thought to exert its therapeutic effects, at least in part, by induction of apoptosis in tumour cells (Brown and Wouters, 1999; Zhivotovsky et al, 1999; Newton and Strasser, 2000; Verheij and Bartelink, 2000). As TRAIL has recently been shown to induce apoptosis effectively in tumour cells (Ashkenazi et al, 1999; Walczak et al, 1999; Dejosez et al, 2000; Nagane et al, 2000; Walczak and Krammer, 2000) but not in normal cells (Walczak et al, 1999; Kim et al, 2001b), this death ligand could be used in combination with IR in anticancer treatment. Therefore, we analysed whether the combined actions of TRAIL and IR effectively overcome the clinically known resistance of human RCCs against induction of apoptosis. 


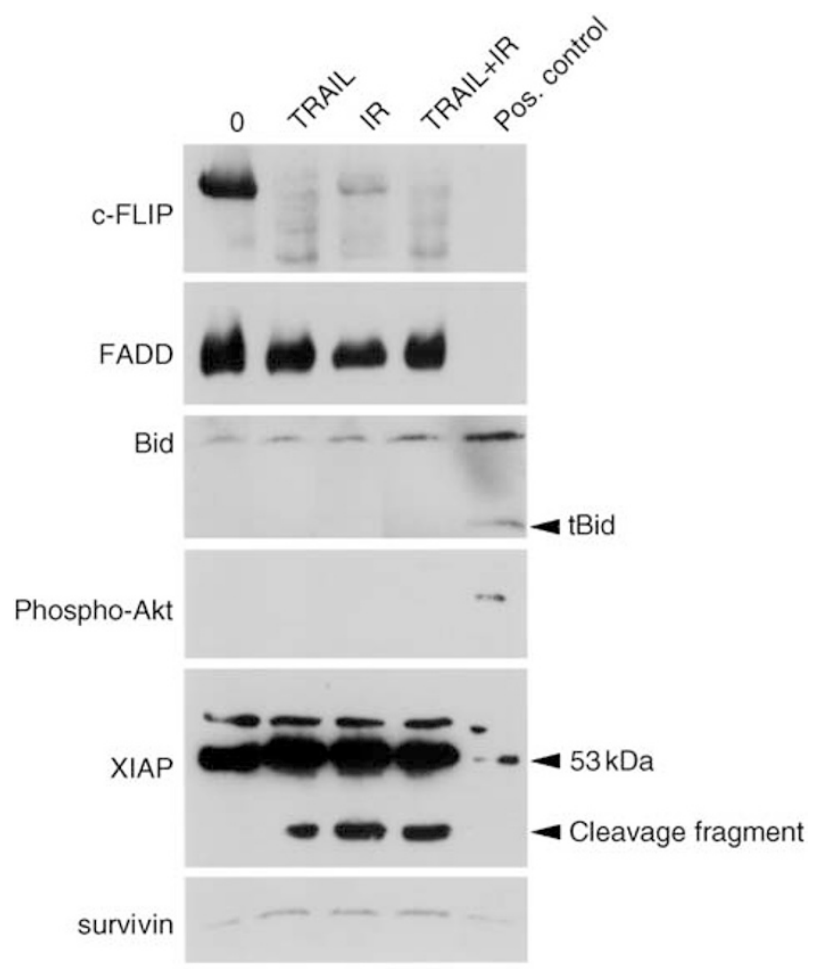

Figure 7 Western blot analysis of apoptosis-regulating proteins in clearCa-22 after exposure to TRAIL $\left(10 \mathrm{ng} \mathrm{ml}^{-1}\right)$ or IR (I Gy) alone and in combination for $12 \mathrm{~h}$. Reduced expression of c-FLIP after exposure to TRAIL and/or IR, whereas expression of FADD and survivin remained unchanged when compared with the control $(0)$. No cleavage of Bid into tBid and absence of active phosphorylated Akt protein after exposure to TRAIL and/or IR. High levels of XIAP protein $(53 \mathrm{kDa})$ before and after exposure to TRAIL and/or IR and appearance of an XIAP cleavage product after exposure to TRAIL and/or IR. (Cleavage of Bid into tBid in 116 cells after exposure to $\mathrm{CHII}$ was used as a positive control; expression of phosphorylated Akt in PDGF-induced NIH-3T3 cells was used as a positive control, as recommended by the manufacturer).

The data presented here demonstrate expression of apoptosisinducing TRAIL-R1- and -R2-receptors in all RCC cell lines. Moreover, recombinant TRAIL was capable of inducing marked apoptosis in three out of eight cell lines. This observation was important in that it proved the existence of a functionally active mechanism of self-destruction in a significant proportion of RCCs, provided that appropriate stimuli can be applied or sensitivity to weak stimuli can be raised. Despite the presence of proapoptotic TRAIL-R1 and -R2 receptors in all cell lines, however, therapeutically relevant doses of IR combined with TRAIL treatment largely failed to increase the apoptotic response in most of our RCC cell lines. Thus, a sensitisation effect with marked enhancement of apoptosis after combined TRAIL and IR treatment was observed in one out of six RCC cell lines only. These observations were at variance with much more favourable recent reports on synergistic effects of TRAIL and IR in breast and colon carcinoma cell lines (Chinnaiyan et al, 2000; Ravi et al, 2001) as well as Jurkat cells (Gong and Almasan, 2000; Kim et al, 2001a). It has to be considered, however, that only short-term effects of TRAIL and IR becoming evident within $72 \mathrm{~h}$ could be assessed under the conditions of our experiments, whereas potential long-term effects of IR were not within the scope of our investigation.

Little is known concerning the mechanisms underlying the resistance to TRAIL and/or IR. However, it is thought that apoptosis induction in response to IR requires an intact p53 system (Lowe et al, 1993), and, accordingly the synergistic effect of
TRAIL and IR in breast carcinomas was reported to depend on a p53 wild-type status (Chinnaiyan et al, 2000). One possible mechanism promoting the synergistic effect of TRAIL and IR might involve the upregulation of TRAIL-R2, known to be a downstream effector gene of p53 ( $\mathrm{Yu}$ et al, 1999). Actually, irradation resulted in an increase of TRAIL-R2 expression in clearCa-22 (which does not harbour mutations in p53-coding regions), thereby possibly rendering this cell line more sensitive to TRAIL-induced apoptosis. Nevertheless, the overall level of apoptosis induction in clearCa-22 after combined exposure to TRAIL and IR was rather low (maximal decrease of cell number: $46.8 \pm 1.5 \%$ of the control) when compared with the effects observed in a colon carcinoma cell line (Ravi et al, 2001) and in different clones of Jurkat cells (Belka et al, 2001; Kim et al, 2001a).

According to current concepts, apoptosis can be induced via at least two distinct, but interconnected pathways that activate different initiator caspases, that is, caspase- 8 and -9 , which converge at the level of executioner caspase-3, -6, and -7. The simultaneous activation of both pathways is thought to result in a strong amplification of the original apoptosis signal (Li et al, 1998; Belka et al, 2000, 2001; Suliman et al, 2001; Joseph et al, 2002). We, therefore, analysed the activation status of these two principal pathways in clearCa-22 after exposure to TRAIL or IR alone and in combination. In these investigations, we could demonstrate cleavage of the executioner caspase- 3 in clearCa-22 only after combined exposure to TRAIL and IR, whereas exposure to TRAIL or IR alone resulted in no or barely detectable caspase- 3 cleavage only. In accordance, cleavage of PARP, known to be a substrate of active caspase-3 (Yang et al, 2001), became evident in clearCa-22 only after combined exposure to TRAIL and IR. Therefore, activation of caspase-3, which was previously shown to be involved in TRAIL- and IR-induced apoptosis in other tumour types (Griffith et al, 1998; Gong and Almasan, 2000; Yamanaka et al, 2000; Belka et al, 2001; Joseph et al, 2001, 2002; Kim et al, 2001a; Nimmanapalli et al, 2001; Rudner et al, 2001; Suliman et al, 2001; Sun et al, 2001; Joseph et al, 2002), is also found in RCCs. At variance with other tumour types (Coelho et al, 2000; Sun et al, 2001; Yang et al, 2001), however, no cleavage of executioner caspase- 6 or -7 became evident in our RCC model system.

Since caspase- 3 can be activated by both principal apoptosis signalling pathways involving the initiator caspase-8 or -9 , respectively, we next analysed the functional contribution of these distinct apoptosis pathways. Thus, we could demonstrate a strong cleavage of the initiator caspase- 8 in clearCa-22 after exposure to TRAIL or IR alone and in combination. These findings are in line with reports demonstrating caspase- 8 cleavage after exposure to TRAIL or IR in RCCs (Pawlowski et al, 2000) and many other tumour types, including carcinomas of the liver, prostate and lungs (Yamanaka et al, 2000; Nimmanapalli et al, 2001; Sun et al, 2001), melanoma (Griffith et al, 1998) and Jurkat cells (Gong and Almasan, 2000; Belka et al, 2001; Kim et al, 2001a; Rudner et al, 2001; Suliman et al, 2001). Activation of caspase- 8 by TRAIL or IR, therefore, seems to be a common reaction pattern in a variety of different tumour types, including RCCs. Of note, a marked downregulation of c-FLIP protein, which is able to inhibit caspase-8 activation (Irmler et al, 1997), became evident in clearCa-22 after exposure to TRAIL and/or IR. Although the role of c-FLIP in inhibiting TRAIL-induced apoptosis is controversial (Griffith et al, 1998; Pawlowski et al, 2000; Wang et al, 2000; Mitsiades et al, 2001), these results suggest that reduced c-FLIP might be involved in the activation of caspase- 8 in RCCs.

Activation of initiator caspase-9 after exposure to TRAIL or IR was reported in carcinomas of the prostate and lung (Nimmanapalli et al, 2001; Joseph et al, 2001; Sun et al, 2001), Ewing's sarcoma (Mitsiades et al, 2001) and Jurkat lymphoma cells (Kim et al, 2001a; Rudner et al, 2001). In contrast, we could not detect any cleavage of inactive procaspase- 9 into active caspase- 9 in clearCa-22 after exposure to TRAIL and/or IR. Therefore, 
transduction of the apoptosis signal via the 'mitochondrial' caspase-9 pathway seems to be blocked in our RCC model system. Our investigation suggests that lack of Bid cleavage might contribute to the failure of caspase- 9 activation. Thus, it is known that active caspase- 8 is able to cleave Bid into tBid, which translocates to mitochondria, causing cytochrome $c$ release and activation of caspase-9 as well as caspase-3 (Li et al, 1998; Belka et al, 2001; Kim et al, 2001a; Nimmanapalli et al, 2001; Suliman et $a l, 2001)$. This interconnection between the caspase- 8 and -9 pathway via Bid is believed to represent a strong amplification loop of the apoptosis signal. However, no cleavage of Bid was detectable in clearCa-22 after exposure to TRAIL and/or IR despite cleavage of caspase- 8 and -3 . Another recently identified regulator of caspase- 9 and Bid is Akt, a serine/threonine protein kinase, which is activated by phosphorylation. Interestingly, the expression of active Akt was found to correlate with TRAIL resistance in prostate carcinomas (Thakkar et al, 2001). Akt exerts its antiapoptotic effects through caspase- 9 inactivation by phosphorylation as well as direct inhibition of Bid cleavage (Thakkar et al, 2001). In clearCa-22, however, expression of active Akt was present neither before nor after exposure to TRAIL and/or IR. In contrast to other tumour types, therefore, Akt seems to be of minor importance for inhibiting Bid cleavage and preventing caspase- 9 activation in our RCC model system.

Moreover, a high basal expression level of the IAP family member XIAP became evident in our RCC cell line clearCa-22. Importantly in this context, we observed the appearance of a cleavage product of XIAP after exposure to TRAIL and/or IR. Since the fragment of XIAP contains the BIR3-Ring domain, which was shown to inhibit specificially the activation of caspase-9 (Deveraux et al, 1999), this cleavage product might also be involved in the deficient activation of caspase-9 in our cell line. In contrast, expression of survivin, another member of the IAP family, which was reported to be downregulated in prostate carcinoma cells after exposure to TRAIL (Nimmanapalli et al, 2001), was not affected in clearCa-22 after exposure to TRAIL and/or IR.

Collectively, our results demonstrate a marked heterogeneity in the responsiveness of human RCC cell lines to TRAIL-mediated apoptosis. Moreover, IR resulted in a sensitisation to TRAILinduced apoptosis in one RCC cell line only. In addition, our observations suggest that TRAIL- and IR-induced apoptosis in RCC is predominantly mediated via the caspase- 8 pathway, whereas the caspase- 9 pathway is not utilised. The missing activation of the caspase- 9 pathway may result from an impaired 'cross talk' with the caspase- 8 pathway because of the lack of Bid cleavage and from the appearance of as XIAP cleavage product known to inhibit caspase- 9 activation. Therefore, the deficient activation of caspase- 9 might contribute to the clinically known resistance of human RCC against IR and also argues against an effective combination therapy with TRAIL and IR in this tumour type.

\section{ACKNOWLEDGEMENTS}

The antibody against c-FLIP was kindly provided by Professor Dr P Krammer (DKFZ, Heidelberg, Germany). Our appreciation is expressed to Mr Ringler for his excellent technical assistance. The results are part of the $\mathrm{PhD}$ thesis of E Caliskan. The work was supported by the 'Deutsche Forschungsgemeinschaft' (DFG).

\section{REFERENCES}

Ashkenazi A, Pai RC, Fong S, Leung S, Lawrence DA, Marsters SA, Blackie C, Chang L, McMurtrey AE, Hebert A, DeForge L, Koumenis IL, Lewis D, Harris L, Bussiere J, Koeppen H, Shahrokh Z, Schwall RH (1999) Safety and antitumor activity of recombinant soluble Apo2 ligand. J Clin Invest 104: $155-162$

Belka C, Rudner J, Wesselborg S, Stepczynska A, Marini P, LeppleWienhues A, Faltin H, Bamberg M, Budach W, Schulze-Osthoff K (2000) Differential role of caspase- 8 and BID activation during radiation- and CD95-induced apoptosis. Oncogene 19: $1181-1190$

Belka C, Schmid B, Marini P, Durand E, Rudner J, Faltin H, Bamberg M, Schulze-Osthoff K, Budach W (2001) Sensitization of resistant lymphoma cells to irradiation-induced apoptosis by the death ligand TRAIL. Oncogene 20: 2190-2196

Brown JM, Wouters BG (1999) Apoptosis, p53, and tumor cell sensitivity to anticancer agents. Cancer Res 59: 1391 - 1399

Chinnaiyan AM, Prasad U, Shankar S, Hamstra DA, Shanaiah M, Chenevert TL, Ross BD, Rehemtulla A (2000) Combined effect of tumor necrosis factor-related apoptosis-inducing ligand and ionizing radiation in breast cancer therapy. Proc Natl Acad Sci USA 97: 1754-1759

Coelho D, Holl V, Weltin D, Lacornerie T, Magnenet P, Dufour P, Bischoff P (2000) Caspase-3-like activity determines the type of cell death following ionizing radiation in MOLT-4 human leukaemia cells. $\mathrm{Br} J$ Cancer 83: $642-649$

Dejosez M, Ramp U, Mahotka C, Krieg A, Walczak H, Gabbert HE, Gerharz CD (2000) Sensitivity to TRAIL/APO-2L-mediated apoptosis in human renal cell carcinomas and its enhancement by topotecan. Cell Death Differ 7: $1127-1136$

Deveraux QL, Leo E, Stennicke HR, Welsh K, Salvesen GS, Reed JC (1999) Cleavage of human inhibitor of apoptosis protein XIAP results in fragments with distinct specificities for caspases. $E M B O J$ 18: $5242-5251$

Di Pietro R, Secchiero P, Rana R, Gibellini D, Visani G, Bemis K, Zamai L, Miscia S, Zauli G (2001) Ionizing radiation sensitizes erythroleukemic cells but not normal erythroblasts to tumor necrosis factor-related apoptosis-inducing ligand (TRAIL)-mediated cytotoxicity by selective upregulation of TRAIL-R1. Blood 97: 2596-2603
Eggert A, Grotzer MA, Zuzak TJ, Wiewrodt BR, Ho R, Ikegaki N, Brodeur GM (2001) Resistance to tumor necrosis factor-related apoptosisinducing ligand-induced apoptosis in neuroblastoma cells correlates with a loss of caspase-8 expression. Cancer Res 61: 1314-1319

Gerharz CD, Moll R, Störkel S, Ramp U, Thoenes W, Gabbert HE (1993) Ultrastructural appearence and cytoskeletal architecture of the clear, chromophilic, and chromophobe types of human renal cell carcinoma in vitro. Am J Pathol 142: 851-859

Gerharz CD, Ramp U, Dejosez M, Mahotka C, Czarnotta B, Bretschneider U, Lorenz I, Müller M, Krammer PH, Gabbert HE (1999) Resistance to CD95 (APO-1/Fas)-mediated apoptosis in human renal cell carcinomas: an important factor for evasion from negative growth control. Lab Invest 79: $1521-1534$

Gerharz CD, Ramp U, Olert J, Moll R, Störkel S, Marx N, Gabbert HE (1994) Cytomorphological, cytogenetic, and molecular biological characterization of four new human renal carcinoma cell lines of the clear cell type. Virchows Arch 424: 403 -409

Gong B, Almasan A (2000) Apo2 ligand/TNF-related apoptosis inducing ligand and death receptor 5 mediate the apoptotic signaling induced by ionizing radiation in leukemic cells. Cancer Res 60: 5754-5760

Griffith TS, Chin WA, Jackson GC, Lynch DH, Kubin MZ (1998) Intracellular regulation of TRAIL-induced apoptosis in human melanoma cells. J Immunol 161: 2833-2840

Igney FH, Krammer PH (2002) Death and anti-death: tumour resistance to apoptosis. Nat Rev Cancer 4: $277-288$

Irmler M, Thome M, Hahne M, Schneider P, Hofmann K, Steiner V, Bodmer JL, Schröter M, Burns K, Mattmann C, Rimoldi D, French LE, Tschopp J (1997) Inhibition of death receptor signals by cellular FLIP. Nature 388: $190-195$

Joseph B, Ekedahl J, Lewensohn R, Marchetti P, Formstecher P, Zhivotovsky B (2001) Defective caspase-3 relocalization in non-small cell lung carcinoma. Oncogene 20: 2877-2888

Joseph B, Marchetti P, Formstecher P, Kroemer G, Lewensohn R, Zhivotovsky B (2002) Mitochondrial dysfunction is an essential step for killing of non-small cell lung carcinomas resistant to conventional treatment. Oncogene 21: $65-77$ 
Kim MR, Lee JY, Park MT, Chun YJ, Jang YJ, Kang CM, Kim HS, Cho CK, Lee YS, Jeong HY, Lee SJ (2001a) Ionizing radiation can overcome resistance to TRAIL in TRAIL-resistant cancer cells. FEBS Lett 501: 179184

Kim K, Takimoto R, Dicker DT, Chen Y, Gazitt Y, El-Deiry WS (2001b) Enhanced TRAIL sensitivity by p53 overexpression in human cancer but not normal cell lines. Int J Oncol 18: 241-247

Li H, Zhu H, Xu CJ, Yuan J (1998) Cleavage of BID by caspase 8 mediates the mitochondrial damage in the Fas pathway of apoptosis. Cell 94: 491 501

Lowe SW, Ruley HE, Jacks T, Housman DE (1993) p53-dependent apoptosis modulates the cytotoxicity of anticancer drugs. Cell 74: 957-967

Mitsiades N, Poulaki V, Mitsiades C, Tsokos M (2001) Ewing's sarcoma family tumors are sensitive to tumor necrosis factor-related apoptosisinducing ligand and express death receptor 4 and death receptor 5 . Cancer Res 61: 2704-2712

Mizutani Y, Nakanishi H, Yoshida O, Fukushima M, Bonavida B, Miki T (2002) Potentiation of the sensitivity of renal cell carcinoma cells to TRAIL-mediated apoptosis by subtoxic concentrations of 5-fluorouracil. Eur J Cancer 38: 167 - 176

Mulders P, Figlin R, deKernion JB, Wiltrout R, Linehan M, Parkinson D, deWolf W, Belldegrun A (1997) Renal cell carcinoma: recent progress and future directions. Cancer Res 57: 5189-5195

Müller M, Wilder S, Bannasch D, Israeli D, Lehlbach K, Li-Weber M, Friedman SL, Galle PR, Stremmel W, Oren M, Krammer PH (1998) p53 activates the CD95 (APO-1/Fas) gene in response to DNA damage by anticancer drugs. J Exp Med 188: 2033-2045

Nagane M, Pan G, Weddle JJ, Dixit VM, Cavenee WK, Su Huang HJ (2000) Increased death receptor 5 expression by chemotherapeutic agents in human gliomas causes synergistic cytotoxicity with tumor necrosis factor-related apoptosis-inducing ligand in vitro and in vivo. Cancer Res 60: $847-853$

Nagata S (2000) Steering anti-cancer drugs away from the TRAIL. Nat Med 6: $502-503$

Newton K, Strasser A (2000) Ionizing radiation and chemotherapeutic drugs induce apoptosis in lymphocytes in the absence of Fas or FADD/ MORT1 signaling: implications for cancer therapy. J Exp Med 191: 195200

Nimmanapalli R, Perkins CL, Orlando M, O'Bryan E, Nguyen D, Bhalla KN (2001) Pretreatment with paclitaxel enhances Apo-2 ligand/tumor necrosis factor-related apoptosis-inducing ligand-induced apoptosis of prostate cancer cells by inducing death receptors 4 and 5 protein levels. Cancer Res 61: 759-763

Oya M, Ohtsubo M, Takayanagi A, Tachibana M, Shimizu N, Murai M (2001) Constitutive activation of nuclear factor- $\kappa B$ prevents TRAILinduced apoptosis in renal cancer cells. Oncogene 20: 3888-3896

Pawlowski JE, Nesterov A, Scheinman RI, Johnson TR, Kraft AS (2000) $\mathrm{NF}-\kappa \mathrm{B}$ does not modulate sensitivity of renal carcinoma cells to TNF $\alpha$ related apoptosis-inducing ligand (TRAIL). Anticancer Res 20: $4243-4256$

Ramp U, Dejosez M, Mahotka C, Czarnotta B, Kalinski T, Wenzel M, Müller M, Krammer P, Gabbert HE, Gerharz CD (2000) Deficient activation of
CD95 (APO-1/Fas)-mediated apoptosis: a potential factor of multidrug resistance in human renal cell carcinoma. Br J Cancer 82: 1851-1859

Ramp U, Mahotka C, Kalinski T, Ebel E, Gabbert HE, Gerharz CD (2001) Topotecan (Hycamtin ${ }^{\mathbb{R}}$ ) responsiveness in human renal carcinoma cell lines of the clear cell and papillary types. Anticancer Res 21: 3509-3518

Ravi R, Bedi GC, Engstrom LW, Zeng Q, Mookerjee B, Gelinas C, Fuchs EJ, Bedi A (2001) Regulation of death receptor expression and TRAIL/ Apo2L-induced apoptosis by NF-кB. Nat Cell Biol 3: 409-416

Reiter RE, Anglard P, Liu S, Gnarra JR, Linehan WM (1993) Chromosome $17 \mathrm{p}$ deletions and p53 mutations in renal cell carcinoma. Cancer Res 53: $3092-3097$

Rudner J, Lepple-Wienhues A, Budach W, Berschauer J, Friedrich B, Wesselborg S, Schulze-Osthoff K, Belka C (2001) Wild-type, mitochondrial and ER-restricted Bcl-2 inhibit DNA damage-induced apoptosis but do not affect death receptor-induced apoptosis. J Cell Sci 114: $4161-4172$

Seol DW, Li J, Seol MH, Park SY, Talanian RV, Billiar TR (2001) Signaling events triggered by tumor necrosis factor-related apoptosis-inducing ligand (TRAIL): caspase- 8 is required for TRAIL-induced apoptosis. Cancer Res 61: $1138-1143$

Suliman A, Lam A, Datta R, Srivastava RK (2001) Intracellular mechanism of TRAIL: apoptosis through mitochondrial-dependent and -independent pathways. Oncogene 20: $2122-2133$

Sun SY, Yue P, Zhou JY, Wang Y, Choi Kim HR, Lotan R, Wu GS (2001) Overexpression of Bcl2 blocks TNF-related apoptosis-inducing ligand (TRAIL)-induced apoptosis in human lung cencer cells. Biochem Biophys Res Commun 280: 788 -797

Thakkar H, Chen X, Tyan F, Gim S, Robinson H, Lee C, Pandey SK, Nwokorie C, Srivastava RK (2001) Pro-survival function of Akt/protein kinase B in prostate cancer cells. J Biol Chem 276: $38361-38369$

Verheij M, Bartelink H (2000) Radiation-induced apoptosis. Cell Tissue Res 301: $133-142$

Walczak H, Krammer PH (2000) The CD95 (APO-1/Fas) and the TRAIL (APO-2L) apoptosis systems. Exp Cell Res 256: 58-66

Walczak H, Miller RE, Ariail K, Gliniak B, Griffith TS, Kubin M, Chin W, Jones J, Woodward A, Le T, Smith C, Smolak P, Goodwin RG, Rauch CT, Schuh JCL, Lynch D (1999) Tumoricidal activity of tumor necrosis factor-related apoptosis-inducing ligand in vivo. Nat Med 5: 157-163

Wang J, Lobito AA, Shen F, Hornung F, Winoto A, Lenardo MJ (2000) Inhibition of Fas-mediated apoptosis by the $\mathrm{B}$ cell antigen receptor through c-FLIP. Eur J Immunol 30: 155-163

Yamanaka T, Shiraki K, Sugimoto K, Ito T, Fujikawa K, Ito M, Takase K, Moriyama M, Nakano T, Suzuki A (2000) Chemotherapeutic agents augment TRAIL-induced apoptosis in human hepatocellular carcinoma cell lines. Hepatology 32: $482-490$

Yang XH, Sladek TL, Liu X, Butler BR, Froelich CJ, Thor AD (2001) Reconstitution of caspase-3 sensitizes MCF-7 breast cancer cells to doxorubicin- and etoposide-induced apoptosis. Cancer Res 61: 348-354

Yu J, Zhang L, Hwang PM, Rago C, Kinzler KW, Vogelstein B (1999) Identification and classification of p53-regulated genes. Proc Nat Acad Sci USA 96: $14517-14522$

Zhivotovsky B, Joseph B, Orrenius S (1999) Tumor radiosensitivity and apoptosis. Exp Cell Res 248: 10-17 